\title{
Alternative Feeding Techniques and Its Effect on Breastfeeding Self-Efficacy
}

\author{
Nora Nabil Hussien", *, Doaa Omar Refaat ${ }^{2}$, Noura Elshahat Arafa $^{3}$ \\ ${ }^{1}$ Department of Family Medicine, Faculty of Medicine-Zagazig University, Zagazig, Egypt \\ ${ }^{2}$ Department of Surgery, Faculty of Medicine-Zagazig University, Zagazig, Egypt \\ ${ }^{3}$ Egyptian Ministry of Health and Population, Zagazig, Egypt
}

Email address:

dr.nora_jana@yahoo.com(N.N. Hussien), doaaomarrefaat65@gmail.com(D. O.Refaat),nouraelshahat1@gmail.com(N.E.Arafa)

${ }^{*}$ Corresponding author

\section{To cite this article:}

Nora Nabil Hussien, Doaa Omar Refaat, Noura Elshahat Arafa. Alternative Feeding Techniques and Its Effect on Breastfeeding Self-Efficacy. Journal of Family Medicine and Health Care. Vol. 5, No. 2, 2019, pp. 22-27. doi: 10.11648/j.jfmhc.20190502.12

Received: July 6, 2019; Accepted: July 30, 2019; Published: August 16, 2019

\begin{abstract}
Breastfeeding self-efficacy is the main part for the success of breastfeeding, achieved by the support from the family and from the community. Self-efficacy is the one's belief in their capabilities, directly related to behavior, feeling, thoughts and motivation of the person. Successful experience increases mom's self-efficacy, and leads to better breastfeeding. This is a cognitive theory that assess mom's self-confidence to breastfeed her baby rather than whether she do succeed to breastfeeding. This paper intended to explore the alternative techniques used to overcome the challenges to exclusive breastfeeding and evaluate breastfeeding self-efficacy of mothers who used alternative techniques. The study is a cross sectional study in Al-Aslogy family health unit, Zagazig city, on women who gave birth to a healthy term baby and initiated breastfeeding in the first seven days postpartum, mothers were interviewed for the Breastfeeding self-efficacy and using alternative techniques for child feeding. This paper revealed that the mean score of Breast-feeding Self-efficacy Scale is $39.93 \pm 5.81$ in very low social class versus $56.6 \pm 13.33$ in high social class with high statistically significant difference and the mean score of BFSE-Score is also statistically higher with exclusive breast feeding than in mothers who used alternative techniques (55.35 \pm 7.09 versus 40.34 \pm 7.81 ) respectively $(\mathrm{p}=0.000)$. It was concluded that Breast-feeding Self-efficacy Score is higher with exclusive breast feeding than with the use of alternative techniques.
\end{abstract}

Keywords: Breastfeeding Self-Efficacy, Alternative Techniques, Lactating Females

\section{Introduction}

Breastfeeding is the normal method for nutrition of the baby, all mothers can breastfeed their babies, as long as they receive education and supported from their families, health care provider and society. Exclusive breastfeeding is recommended for up to 6 months of the baby's age, and to be continued with complementary feeds up to two years old [1].

Breastfeeding is affected by factors as age, level of education, structure of family, socioeconomic status, wanted pregnancy, health problems during pregnancy, previous experience with breastfeeding, the working status of the mother, education about breastfeeding, the provider education about breastfeeding and the type of delivery [2].

There are barriers to exclusive breastfeeding, and so there is a need for supplements and use of alternative techniques, which may be maternal (as delayed milk secretion, breast disease and medication), or related to the new born baby (as dehydration, hypoglycemia and hyperbilirubinaemia) [3].

Breastfeeding self-efficacy is the main part for the success of breastfeeding, achieved by the support from the family and from the community. Self-efficacy is the one's belief in their capabilities, directly related to behavior, feeling, thoughts and motivation of the person. Successful experience increases mom's self-efficacy and leads to better breastfeeding [4]. It is defined as a mother's confidence in her ability to breastfeed her new infant [5] and has been positively associated with breastfeeding duration and exclusivity in various cultures and age groups $[6,7]$. 


\section{Subjects and Methods}

\subsection{Study Design}

The study was a descriptive cross sectional study.

\subsection{Study Area}

The family health unit of Al-Aslogy selected randomly fromZagazig city, Egypt.

\subsection{Study Population}

Mothers who gave birth to a healthy term infant, and initiated breastfeeding in the first seven days postpartum, attending the family health unit for child vaccine of 6 months of age. The mothers were excluded if they had given formula for the baby from the start, or if the baby was preterm/post term and if the baby was admitted to intensive care.

\subsection{Sample Size and Sampling Method}

The family health unit was chosen by simple random sampling from Zagazig city. Considering the previous score recorded for Breastfeeding Self-efficacy in lactating mothers. The sample size was calculated by open EPI info version 6; at a confidence level $95 \%$ to be 196 lactating mother to be included in the study sample. The researcher visited the family health unit once weekly on the day scheduled for child vaccination, mothers who met the inclusion criteria were interviewed personally. A pilot study was carried out to ascertain the clarity, applicability of study tools it was done on $10 \%$ of total sample and it was included in the total sample of the research as there were no modifications done in the tools.

\subsection{Data Collection Technique}

The researcher visited the family health unit once weekly on the day scheduled for the 4 th dose of child vaccination. The attending mothers fulfilling the study criteria were interviewed for sociodemographic variables and the social class was evaluated using El-Gilany et al [8]. Also the type of delivery, breastfeeding and usage of alternative techniques during first week after delivery, and completed the breast feeding self-efficacy scale short form (BFSE-SF) [9].

\subsection{Data Collection Tools}

1. A-Socio demographic variables (age, education, occupation, marital status, etc.) [8].

2. The BSES-SF: an instrument developed to measure breastfeeding confidence. It consists of 14-item all are preceded by the statement "I can always" and are anchored by a 5-point Likert-type scale, with $1=$ not at all confident and 5=always confident. All the items are presented positively and the scores are summed up to produce a final score ranging from 14 to 70 , with the higher scores indicating better breastfeeding self-efficacy [9].

\subsection{Data Analysis}

The collected data were presented by tables, and analyzed by computer using Statistical Package of Social Services version 19 (SPSS). ANOVA and student t-test were used to test significance. The results will be considered statistically significant when the significant probability is less than or equal to $5 \%(\leq 0.05)$.

\subsection{Ethical Clearance}

Official permission was obtained for enforcement of the study. Approval was obtained from Institutional Review Board (IRB), faculty of medicine at Zagazig University.

\section{Results}

About half of the studied lactating females exclusively breast fed their babies without any assistant methods (54.6\%) (Table 1).

Table 1. Using alternative techniques versus natural breastfeeding during the 1st week after delivery among the studied lactating females (No=196).

\begin{tabular}{lll}
\hline \multirow{2}{*}{ Item } & \multicolumn{2}{l}{ Lactating females $(\mathbf{n = 1 9 6})$} \\
\cline { 2 - 3 } & No. & $\mathbf{\%}$ \\
\hline Alternative techniques use & 89 & 45.4 \\
Exclusive breast feeding & 107 & 54.6 \\
\hline
\end{tabular}

The most frequently used alternative techniques are tight nipple bottles are used once, till 5 times and more than 5 times in $(6.7 \%, 22.5 \%$ \& $27.0 \%)$ respectively, followed by syringe which are used once, till 5 times and more than 5 times in $(11.4 \%, 23.9 \% \& 9.1 \%)$ respectively, wide nipple bottles are used in only $18 \%$, followed by cups and feeding tubes $(7.9 \%$ $\& 5.7 \%$ ) respectively (Table 2 ).

Table 2. Frequency of usage of alternative techniques with breast feeding during the 1st week after delivery among the studied lactating females (No=89).

\begin{tabular}{|c|c|c|c|c|c|c|c|c|}
\hline \multirow{2}{*}{ Items } & \multirow{2}{*}{$\begin{array}{l}\text { No } \\
\text { no } \\
\end{array}$} & \multicolumn{3}{|c|}{ Once } & \multicolumn{2}{|c|}{ Till 5 times } & \multicolumn{2}{|c|}{ More than 5 times } \\
\hline & & $\%$ & no & $\%$ & no & $\%$ & no & $\%$ \\
\hline Tight nipple bottles & 39 & 43.8 & 6 & 6.7 & 20 & 22.5 & 24 & 27.0 \\
\hline Wide nipple bottles & 73 & 83.0 & 8 & 9.1 & 8 & 9.1 & 0 & 0.0 \\
\hline Syringe & 49 & 55.7 & 10 & 11.4 & 21 & 23.9 & 8 & 9.1 \\
\hline Syringe and fingers & 89 & 100.0 & 0 & 0.0 & 0 & 0.0 & 0 & 0.0 \\
\hline Tube and fingers & 89 & 100.0 & 0 & 0.0 & 0 & 0.0 & 0 & 0.0 \\
\hline Cup & 81 & 92.0 & 1 & 1.1 & 1 & 1.1 & 5 & 5.7 \\
\hline Nipple Shield & 89 & 100.0 & 0 & 0.0 & 0 & 0.0 & 0 & 0.0 \\
\hline
\end{tabular}


About $45 \%$ of women who use alternative techniques for breast feeding complained of pain due to nipples cracks, $70 \%$ of them stated that pain was mild to moderate pain; only $4.5 \%$ reported labor related pain in the form of caesarian section pains or abdominal pain, ranged from mild to severe (Table 3 ).

Table 3. Causes of usage of alternative techniques with breast feeding during the 1st week after delivery among the studied lactating females (No=89).

\begin{tabular}{|c|c|c|}
\hline \multirow{2}{*}{ items } & \multicolumn{2}{|c|}{ lactating femalesused alternative techniques $(\mathrm{N}=89)$} \\
\hline & no & $\%$ \\
\hline Nipple pains $(n=82)$ & 82 & 92.1 \\
\hline Blisters & 10 & 11.2 \\
\hline Cracks & 40 & 44.9 \\
\hline bleeding & 14 & 15.7 \\
\hline scratches & 11 & 12.4 \\
\hline pain without apparat cause & 7 & 7.8 \\
\hline No pain & 5 & 6 \\
\hline mild & 22 & 26.8 \\
\hline moderate & 36 & 43.9 \\
\hline severe & 13 & 15.8 \\
\hline very severe & 6 & 7.3 \\
\hline Labor related pain $(\mathrm{n}=4)$ & 4 & 4.5 \\
\hline caesarian section pains & 2 & 50.0 \\
\hline \multicolumn{3}{|l|}{ Level of labor related pain } \\
\hline mild & 2 & 50.0 \\
\hline severe & 2 & 50.0 \\
\hline Tiredness $(n=3)$ & 3 & 3.3 \\
\hline
\end{tabular}

The mean score of Breast-feeding Self-efficacy Scale is 47.15 \pm 10.58 , it ranged from 28-66, BFSE scale is ranged from $37-56$ (IQR) in $50 \%$ of the studied females (Table 4 ).

Table 4. Breast-feeding Self-efficacy Scale-Short Form among the studied lactating females (No=196).

\begin{tabular}{llll}
\hline BFSES & Mean \pm SD & Median & Min-Max \\
\hline Breastfeeding Self-efficacy & $47.16 \pm 10.58$ & 49 & $28-66$ \\
\hline
\end{tabular}

The mean score of Breast-feeding Self-efficacy Scale is statistically higher with exclusive breast feeding than in assisted breast feeding (55.35 \pm 7.09 versus 40.34 \pm 7.81$)$ respectively ( $\mathrm{p}=0.000)$ (Table 5).

Table 5. Breastfeeding Self-efficacy of lactating Mothers in relation to feeding technique among the studied lactating females (No=196).

\begin{tabular}{|c|c|c|c|c|}
\hline Breastfeeding Self-efficacy & Assisted breast feeding $(\mathrm{N}=89)$ & Exclusive breast feeding $(\mathrm{N}=107)$ & t-test & P-value \\
\hline Mean \pm SD & $40.34 \pm 7.81$ & $55.35 \pm 7.09$ & -14.09 & $0.000 *(\mathrm{HS})$ \\
\hline
\end{tabular}

Test: student $\mathrm{t}$ test*P-value $<0.05$ is significantHS (highly significant).

The mean score of Breast-feeding Self-efficacy Scale is $39.93 \pm 5.81$ in very low social class versus $56.6 \pm 13.33$ in high level social class with high statistically significant difference, also there is high statistically significant difference regarding occupation and education (Table 6).

Table 6. Breastfeeding Self-efficacy of lactating mothers in relation to sociodemographic data among the studied lactating females (No=196).

\begin{tabular}{|c|c|c|c|c|c|c|c|}
\hline \multirow{2}{*}{ Variable } & \multirow{2}{*}{$\mathbf{N}$} & \multicolumn{4}{|c|}{ Breastfeeding Self-efficacy } & \multirow{2}{*}{ F test } & \multirow{2}{*}{ P-value } \\
\hline & & Mean & SD & MIN & MAX & & \\
\hline \multicolumn{8}{|l|}{ Age } \\
\hline$>20$ & 10 & 46.20 & 12.19 & 28.00 & 65.00 & \multirow{4}{*}{0.063} & \multirow{4}{*}{$0.980(\mathrm{NS})$} \\
\hline $20-$ & 70 & 47.47 & 11.03 & 29.00 & 65.00 & & \\
\hline $25-$ & 81 & 47.17 & 10.25 & 29.00 & 64.00 & & \\
\hline $30-35$ & 35 & 46.77 & 10.38 & 30.00 & 66.00 & & \\
\hline \multicolumn{6}{|l|}{ Education } & \multirow{8}{*}{17.981} & \multirow{8}{*}{$0.000 *(\mathrm{HS})$} \\
\hline Illiterate & 7 & 37.85 & 2.19 & 33.00 & 39.00 & & \\
\hline Primary/Preparatory education & 10 & 35.00 & 2.74 & 30.00 & 38.00 & & \\
\hline Secondary & 60 & 41.80 & 8.00 & 28.00 & 52.00 & & \\
\hline Intermediate/institute & 16 & 56.31 & 10.75 & 29.00 & 63.00 & & \\
\hline University & 96 & 50.02 & 9.48 & 30.00 & 65.00 & & \\
\hline Post graduate & 7 & 59.57 & 10.52 & 36.00 & 66.00 & & \\
\hline Occupation & & & & & & & \\
\hline
\end{tabular}




\begin{tabular}{|c|c|c|c|c|c|c|c|}
\hline \multirow{2}{*}{ Variable } & \multirow{2}{*}{$\mathbf{N}$} & \multicolumn{4}{|c|}{ Breastfeeding Self-efficacy } & \multirow{2}{*}{ F test } & \multirow{2}{*}{ P-value } \\
\hline & & Mean & SD & MIN & MAX & & \\
\hline Non-working/house wife & 126 & 44.34 & 10.07 & 28.00 & 62.00 & \multirow{3}{*}{15.359} & \multirow{3}{*}{$0.000 *(\mathrm{HS})$} \\
\hline Semi-professional/clerk & 45 & 50.91 & 8.88 & 29.00 & 66.00 & & \\
\hline Professional & 25 & 54.56 & 10.53 & 33.00 & 65.00 & & \\
\hline \multicolumn{7}{|l|}{ Social class } & \multirow{4}{*}{$0.000 *(\mathrm{HS})$} \\
\hline very low & 15 & 39.93 & 5.81 & 36.00 & 55.00 & \multirow{3}{*}{7.905} & \\
\hline Low & 61 & 44.47 & 10.98 & 28.00 & 62.00 & & \\
\hline High level & 10 & 56.60 & 13.33 & 30.00 & 65.00 & & \\
\hline
\end{tabular}

Test: ANOVA*P-value $<0.05$ is significantHS (highly significant).

NS (Non-significant).

The mean score of Breast-feeding Self-efficacy Scale is $39.93 \pm 5.81$ in mothers without previous breast-feeding experience versus $47.14 \pm 10.68$ in mothers with previous breast-feeding experience with high statistically significant difference, also there is statistically significant difference regarding type of delivery (Table 7).

Table 7. Breastfeeding Self-efficacy of lactating Mothers in relation to mode of delivery and previous breast-feeding experience among the studied lactating females $(\mathrm{No}=196)$.

\begin{tabular}{|c|c|c|c|c|c|c|c|}
\hline \multirow{2}{*}{ Variable } & \multirow{2}{*}{$\mathbf{N}$} & \multicolumn{4}{|c|}{ Breastfeeding Self-efficacy } & \multirow{2}{*}{ test } & \multirow{2}{*}{ P-value } \\
\hline & & Mean & SD & MIN & Max & & \\
\hline \multicolumn{8}{|l|}{ Type of delivery } \\
\hline vaginal labor & 59 & 46.20 & 11.27 & 28.00 & 64.00 & \multirow{4}{*}{$\# 2.074$} & \multirow{4}{*}{$0.047(\mathrm{~S})$} \\
\hline vaginal labour with suction & 1 & 30.00 & & 30.00 & 30.00 & & \\
\hline selective C.S & 76 & 46.00 & 10.09 & 29.00 & 66.00 & & \\
\hline elective C.S & 60 & 49.85 & 10.02 & 29.00 & 65.00 & & \\
\hline \multicolumn{8}{|c|}{ Previous breast-feeding experience } \\
\hline no & 68 & 39.93 & 5.81 & 36.00 & 55.00 & \#\#6.12 & $<0.0001(\mathrm{HS})$ \\
\hline
\end{tabular}

\#Test: ANOVA \#\#test: student t-test *P-value $<0.05$ is significant.

HS (highly significant)S (significant).

\section{Discussion}

Exclusive breastfeeding is essential for both the infant and the mother; it is affected mainly by the mother's self-efficacy to do the act of breastfeeding, and the support she perceives from the family, the physician, and the community. Lack of this causes the female to choose alternative techniques to feed her baby.

The results in Table 1 showed that about half of the studied lactating females exclusively breast feed their babies without any assistant methods (54.6\%) during the first week postpartum. That was much lower than Keemer's study that showed that breastfeeding more than 7days postpartum was done by 124 of 128 participants, while others stopped before the 7th day postpartum [10].

Another study evaluated exclusive breastfeeding for 5 months or more in Sri-Lanka to be $81.3 \%$ the difference may be attributed to the duration of evaluation of breastfeeding [11]. Also in Bhutan which was ranked the lowest country in the South Asian region for exclusive breastfeeding according to the WHO, reported the prevalence of exclusive breastfeeding practice decreased with age from $97 \%$ at 1 month to $58 \%$ for 5 -to 6 -month-old infants [12].

Table 2 shows that the studied lactating mothers don't use syringe and fingers, tube and fingers and nipple shield, as regard the most frequently used alternative techniques,tight nipple bottles are used once, till 5 times and more than 5 times in $(6.7 \%, 22.5 \%$ \& $27.0 \%)$ respectively, followed by Syringe which are used once, till 5 times and more than 5 times in $(11.4 \%, 23.9 \% \& 9.1 \%)$ respectively, wide nipple bottles are used in only $18 \%$, followed by cups and feeding tubes ( $7.9 \%$ \& 5.7\%) respectively.

This is close to Keemer's study that showed that the most commonly used alternative technique is bottle with regular nipple 48among 62 who used alternative techniques, after it comes the syringes $27 / 62$ then bottle with wide nipple $21 / 62$, nipple shield $17 / 62$, then cup feeding used by $12 / 62$ lactating females, and the supply line used by only once by a primipara [10].

Table 3 showed that about half of women who used alternative techniques for breast feeding complained of pain due to nipples cracks $(45.5 \%), 70 \%$ of them stated that pain was mild to moderate pain; only $4.5 \%$ reported labor related pain in the form of caesarian section pains or abdominal pain, ranged from mild to severe.

While according to keemer's study $40.3 \%$ of the females used alternative methods due to nipple pain, the baby wouldn't settle $40.3 \%$, not enough milk or colostrum $37.1 \%$, and fatigue $37.1 \%$ mother reported poor latch on $37.1 \%$, losing $10 \%$ of baby's birth weight, and pain associated with birth are other causes of the usage of alternative techniques [10].

Table 4 demonstrated that the mean score of Breast-feeding Self-efficacy Scale score is $47.15 \pm 10.58$, it ranged from 28-66, BFSE scale is ranged from 37-56 (IQR) in $50 \%$ of the studied females. This was lower than Nursan 
presenting that BSES-SF mean 58.61, SD 8.93, range, 16 to 70 [9], but it is so close to another study in Malaysia reporting a mean score of Breastfeeding Self-Efficacy of $51.78(\mathrm{SD}=11.94)[13]$.

Table 5 shows that the mean score of Breast-feeding Self-efficacy Scale is statistically higher with exclusive breast feeding than in mothers who used assisted breast feeding $(55.35 \pm 7.09$ versus $40.34 \pm 7.81)$ respectively $(p=0.000)$. That was in consistent with keemer study BFSE-score was statistically higher with exclusive breastfeeding than with using alternative techniques $(58.32 \pm 7.40$ versus $43.43 \pm 12.9)$ respectively [10].

Table 6 shows that the mean score of Breast-feeding Self-efficacy Scale is $39.93 \pm 5.81$ in very low social class versus $56.6 \pm 13.33$ in high level social class with high statistically significant difference, also there is high statistically significant difference regarding occupation and education. This was inconsistence with a previous study in Iran reporting that sufficient incomes, compared to those with insufficient incomes, had significantly higher breastfeeding self-efficacy scores, and the mothers with rental houses had significantly lower self-efficacy, compared to their peers with owned properties [14].

Unlike Nursan's study that showed no significant relationship between the scale score and socioeconomic status (62\% had moderate socioeconomic status), or with mother's age $(49.4 \%$ aged $18-26)$, or with maternal education $(46.1 \%$ were primary school graduated), while $89.5 \%$ were unemployed [9].

Table 7 shows that the mean score of Breast-feeding Self-efficacy Scale is $39.93 \pm 5.81$ in female without previous breast-feeding experience versus $47.14 \pm 10.68$ in females with Previous breast-feeding experience with high statistically significant difference, also there is statistically significant difference regarding type of delivery.

This is consistent with Nursan's study that showed that the relation was significant between scale score and mom's experience with breastfeeding that is higher than those with no previous experience to breastfeeding, and mothers who had ceaserian section were $56.6 \%$, and those who had vaginal delivery were $43.3 \%$, no difference, but vaginal more than caeserian delivery [9].

And also in another study done on 294 postpartum mothers in Brazil used the Portuguese version of Breastfeeding Self-Efficacy Scale-Short Form (BSES-SF), a significant relationships were found between postpartum breastfeeding self-efficacy with previous experience to breastfeed ( $\mathrm{r}=0.129$; $\mathrm{p}=0.027)$ and previous breastfeeding duration $(\mathrm{r}=0.153$; $\mathrm{p}=0.009)$ [15].

\section{Conclusion}

In this study $54.6 \%$ exclusively breastfed their babies. Those who used alternative feeding methods in the first week after birth, expressed that the use of bottle with tight nipple are $27 \%$, and the cause was due to: nipple fissures $45 \%$, with mild to moderate pain as $70 \%$, labor pain was only $4.5 \%$.
The mean score of Breast-feeding Self-efficacy Scale-short form is $47.15 \pm 10.58$, it ranged from $28-66$, the mean score of Breast-feeding Self-efficacy Scale is statistically higher with exclusive breast feeding than in assisted breast feeding $(55.35 \pm 7.09$ versus $40.34 \pm 7.81)$ respectively $(p=0.000)$.

\section{References}

[1] World Health Organization. Breastfeeding 2018. http://www.who.int/topics/breastfeeding/en/.

[2] Burcu K, Ilknur D, Remzye S, Seda S, Buket D, Kale K. The relation between breastfeeding self-efficacy and starting times of supplementary food. International journal of caring science 2017; 11 (1): 231-238.

[3] Kellams A, Harrel C, Omage S, Gregory C, Rosen-Carole C. The Academy of Breastfeeding Medicine: ABM Clinical Protocol \#3: Supplementary feedings in the healthy term breastfed neonate. Breast feeding medicine 2017; 12 (3): 1-11.

[4] Vincent A. The effect of breastfeeding self-efficacy on breastfeeding initiation, exclusivity and duration, Doctoral Studies, Walden University Scholar Works 2015: 1-66. https://scholarworks.waldenu.edu/cgi/viewcontent.cgi?referer $=$ https: $/ /$ www.google.com.eg $/ \&$ httpsredir=1\&article $=2863 \&$ co ntext $=$ dissertations.

[5] Dennis CL. Theoretical underpinnings of breastfeeding confidence A self-efficacy framework. Journal of Human Lactation. 1999; 15: 195-201. doi: 10.1177/089033449901500303.

[6] Blyth R, Creedy DK, Dennis CL, et al. Effect of maternal confidence on breastfeeding duration: An application of breastfeeding self-efficacy theory. Birth. 2002; 29: 278-284. doi: 10.1046/j.1523-536X.2002.00202.x.

[7] AluşTokat M, Okumuş H, Dennis CL. Translation and psychometric assessment of the Breast-feeding Self-Efficacy Scale-Short Form among pregnant and postnatal women in Turkey. Midwifery. 2010; 26: 101-108. doi: 10.1016/j.midw.2008.04.002.

[8] El-Gilany A, El-Wehady A, El-Wasify M. Updating and validation of socioeconomic status scale for health research in Egypt. East Mediterranean Health J 2012; (18): 962-8.

[9] Nursan C, Dilek K, Sevin A. Breastfeeding Self-efficacy of Mothers and the Affecting Factors.2014; 14 (3): 327-335. DOI: 10.5294/aqui.2014.14.3.5.

[10] Keemer F. Breastfeeding self-Efficacy and alternative techniques to overcome maternal or infant breastfeeding challenges: a retrospective study. Thesis, Queensland University of Technology.2011; Page 96-103. https://eprints.qut.edu.au/47144/1/Frances_Keemer_Thesis.pdf.

[11] Ratnayake $\mathrm{H}$ and Rowel D. Prevalence of exclusive breastfeeding and barriers for its continuation up to six months in Kandy district, Sri Lanka. International Breastfeeding Journal 2018; $13: \quad 36$ https://doi.org/10.1186/s13006-018-0180-y.

[12] Tshering, D, GurungM, Wangmo N, Pelzom D, Tejativaddhana $P$ et al. Prevalence of Exclusive Breastfeeding and Factors Associated With Exclusive Breastfeeding of Children in Trongsa District, Bhutan. Asia Pacific Journal of Public Health. 2018; Vol. 30 (4) 369-377 DOI: 10.1177/1010539518768573. 
[13] Abdul Hamid S and Zaidi S. Breastfeeding Self-efficacy in Malaysian Expectant Mothers. Centre of Nutrition and Dietetics Studies, Faculty of Health Sciences, UniversitiTeknologi Mara, Malaysia. 2018. https://publichealthconference.co/wp-content/uploads/2018/07 /24.-Syahrul-Bariah-Abdul-Hamid PhD.pdf.

[14] Maleki-Saghooni N, Barez M, Moeindarbari S, Karimi F. Investigating the Breastfeeding Self-Efficacy and its Related Factors in Primiparous Breastfeeding Mothers. Int J Pediatr. 2017; 5 (12): 6275-6283. DOI: 10.22038/IJP.2017.25656.2182.
[15] Dodt R, Ximenes L, Almeida P, Batista M, Dennis C. Psychometric and maternal sociodemographic assessment of the breastfeeding self-efficacy scale-short form in a brazilian sample. Journal of Nursing Education and Practice 2012; 2 (3): $1-8$. 